DOI: $\underline{10.17805 / g g z .2018 .5 .3}$

\title{
Онтологии биотехнологических рисков: социогуманитарные методологии и технонаука
}

Р. Р. Белялетдинов

Институт философии РАН

В статье рассматривается проблема генезиса онтологий социогуманитарных рисков, возникающих в связи с развитием биотехнологий. Гибридный характер сосуществования технонаучного и сочиального миров определяется как слияние соииального ожидания и технологий. Вместе с тем уже сложившиеся сочиогуманитарные практики остаются важными теоретико-методологическими матрицами, в рамках которых определяются биотехнологические онтологии рисков. К этим методологиям можно отнести биоэтику, наноэтику, исследования науки и технологий (STS), проблематику улучшения человека, гуманитарную экспертизу. Результатом применения этих методологий к технонаучным биотехнологическим проектам является не только онтологизация рисков, но и их деонтологизачия в процессе фактической реализачии биотехнологических проектов. Этот процесс рассматривается на примере концепџии генетизачии общества.

Ключевые слова: биоэтика; технонаука; улучшение человека; гибридизаиия науки; паблики; исследования науки и технологий; STS; гуманитарная экспертиза; генетизащия общества

\section{Ontologies of Biotechnological Risks: Social and Humanities Methodologies and Technoscience} R. R. Belyaletdinov Institute of Philosophy, Russian Academy of Sciences

The article deals with the problem of the genesis of the ontologies of social and humanitarian risks associated with the development of biotechnologies. The hybrid character of the coexistence of the technoscientific and social worlds is defined as the fusion of social expectation and technologies. At the same time, already established social and humanitarian practices remain important theoretical and methodological matrices, within which biotechnological risk ontologies are determined. These methodologies include bioethics, nanoethics, science and technology studies (STS), human improvement issues, and humanitarian expertise. The 
result of the application of these methodologies to technoscientific biotechnological projects is not only the ontologization of risks, but also their deontologization in the process of implementing biotechnological projects in practice. The author examines this process in the case of the concept of the geneticisation of society.

Keywords: bioethics; techno-science; human improvement; hybridization of science; publics; science and technology studies; STS; humanitarian expertise; ge-neticisation of society

\section{ВВЕДЕНИЕ}

Проблематика социогуманитарных рисков развития биотехнологий связана с технонаучной структурой науки, с одной стороны, и различными методами концептуализации биотехнологических рисков - с другой. Теоретическая репрезентация биотехнологических рисков способна выстраивать целостную картину, например, генетизации общества, но не всегда позволяет определить комплексность влияния биотехнологических инноваций в реальной жизни.

Разнообразие социогуманитарных методологий репрезентирует теоретические матрицы рисков - социальные, гуманитарные, медицинские и философско-этические. Вместе с тем технонаучный характер современной науки не только служит реальным контекстом для социогуманитарной рефлексии, посвященной проблеме биотехнологических рисков, но и оказывает влияние на аудиторию экспертных заключений. Во многом онтология рисков попадает в зависимость от тех, кто читает и оценивает выводы экспертиз. В технонауке адресат прочтения рисков меняется: экспертные сообщества вынуждены конкурировать с пабликами и проводить экспертизу технонаучных мнимостей, которые эти паблики разделяют и транслируют (Rommetveit, Wynne, 2017: 134).

\section{РИСК, ТЕХНОНАУКА И \\ ЭПИСТЕМОЛОГИЧЕСКИЙ СДВИГ}

Проблема биотехнологических рисков связана не столько с признанием императива ответственности (Тищенко, 1992: 106), сколько с обоснованием того, как философски она может быть представлена в социогуманитарных контекстах, порождаемых технонаукой. Иными словами, речь идет об обосновании и признании определенных универсальных принципов, с одной стороны, и философском, этическом и социогуманитарном анализе конкретных ситуаций, возникающих с подачи биотехнологий, — с другой. 
Стремление человека к саморазвитию в обществе, которому доступны все новые виды биотехнологических инноваций, естественным образом воплощается в новые, нередко революционные формы, а философские представления о личностной автономии, социальной справедливости и благе придают этим интенциям гуманитарное содержание и позволяют заново обретать телесную и этико-философскую целостность человека (Попова, 2017).

Гибридный характер взаимодействия технонаучного и социального пространств становится ключевой характеристикой современного мира: войны ведутся дронами под прямым наблюдением президентов; защита таких фундаментальных свобод, как приватность, входит в задачи инженерии, риск-менеджмента и дизайна, становится объектом возникающих информационных и коммуникационных технологических систем. Экспертам приходится считаться с мнением захваченной воображением публики, не любящей и не понимающей неопределенности, свойственной модернизму (Rommetveit, Wynne, 2017: 134), и, как следствие, готовой одобрять порой более чем смелые технонаучные проекты с точки зрения социогуманитарных и философских аргументов.

В связи с гибридизацией технонауки биотехнологические проекты обретают форму утопии, основанной на ожидании и готовности к радикальным формам риска. В этом контексте возникает необходимость тестировать новые формы технонаучного знания. Эпистемологический сдвиг (ibid: 139) имеет инструментальное значение для освоения технологий и основывается на том, что способом валидации технонаучного знания является строительство устройств, которые бы «работали» на основе технонаучного знания. Основные принципы неолиберальной теории-в-практике подразумевают: во-первых, сложность технонаучного и непредсказуемость инновационного процесса и, во-вторых, использование адаптивного принципа «запусти это и смотри, что из этого получится». Проводивший философский анализ нанотехнологий французский философ Ж. Дюпюи пришел к выводу, что их целью была конвергентная попытка преодолеть ограничения, даже такие, как смертность человека, с помощью грядущей технонаучной инженерии. Разрушение границ, предложенное в рамках НБИК-инициативы, основывается не столько на некоторой единой субстанции, присущей всем вещам, сколько на основании надежды на комплекс объединенных принципов (кибернетически) организованного контроля. Нанотехнологии обещают контроль на совершенно новом уровне - нанометра, и в новом масштабе - всеобъемлюще. Видимой стороне технологического ожидания сопутствуют скрытые усилия, направленные на командную предикцию и контроль (ibid: 134). Эпистемологический 
сдвиг действует в обход философских и этических концепций и, в рамках мысленного эксперимента, предлагает новые типы контроля, направленного в том числе и на освобождение от рисков. Столкновение онтологий рисков технонауки и онтологий рисков, сложившихся в социогуманитарных дискурсах, становится одним из основных событий современной науки в ее философском измерении.

\section{ГЕНЕЗИС ОНТОЛОГИЙ РИСКОВ}

Социогуманитарные методологии остаются важной теоретикометодологической составляющей при исследовании проблемы биотехнологических рисков. Можно выделить ряд подходов или матриц, которые так или иначе применяются для социогуманитарного сопровождения развития биотехнологий. Прежде всего это биоэтика, которая широко опирается на философские концепции персональной автономии и стандарты оказания медицинской помощи. Кроме того, биоэтика является междисциплинарной системой знаний, предлагающей синтез этической, философской и правовой проблематик взаимоотношений врача и пациента.

Вторая матрица связана с расширением биотехнологий за счет конвергенции, т. е. слияния с другими технологиями. Этика нанотехнологий (наноэтика) развивается как разработка терминологического языка, который бы отражал реалии нанотехнологий, вливающихся в биотехнологии.

Третья методологическая матрица - исследования науки и технологий (STS), где исследуются технологии (в том числе и биотехнологии), как факторы, включенные в социальную среду, испытывающие ее влияние - культурное, социальное и медийное.

К четвертой матрице предлагается отнести критический анализ идей биотехнологического улучшения человека, основанных на проектировании человека в отрыве от базовых этических концепций и инициирующих философское обсуждение в рамках эпистемологических сдвигов, где в виде мысленного эксперимента может быть представлено будущее человека.

Пятая матрица - гуманитарная экспертиза, в которой представлены традиции отечественной гуманитарной и философско-этической рефлексии развития биотехнологий, связь биотехнологий и технонауки, раскрывается идея философии как философской экспертизы современных биотехнологий.

Становление биоэтики связано с раскрытием подробностей биомедицинских экспериментов над человеком, проходивших в нацистских и японских концентрационных лагерях (Yudin, 2010). Однако результат Нюрнбергского процесса над нацистскими врачами можно рассматривать и как пере- 
ломный момент, после которого начался период переосмысления взаимоотношений врача и пациента, которое продолжает изменяться в направлении ослабления медицинского патернализма.

На первом этапе формирования современной биоэтики принятие Нюрнбергского кодекса о проведении исследований с участием человека и введение принципа информированного согласия послужили началом для создания концепции, определяющей условия биомедицинских экспериментов.

Особенностью биоэтики стало экспериментирование с аргументацией, что в целом соответствует ее междисциплинарной природе. Таким образом, биоэтика сегодня «не столько формальная дисциплина, сколько совпадение многих дисциплин, входящих в более широкий общественный дискурс» (Jonsen, 2010: 49; пер. наш. - P. Б.), связанный с развитием биотехнологий.

Можно сказать, что биоэтика является и инструментом разрешения ситуаций, возникающих в повседневной жизни между врачом и пациентом, биомедициной и обществом, политиком и запросами научного сообщества на поддержку научных исследований.

Значительная роль в определении природы рисков сегодня принадлежит специализированным ответвлениям этики - наноэтике, нейроэтике и др. А. Грунвальд отмечает две особенности нанотехнологий: их высокий потенциал в случае применения для улучшения человека и высокую степень конвергенции этических аспектов применения нанотехнологий (Grunwald, 2005).

В настоящее время сосуществуют два видения этики нанотехнологий. Согласно первому подходу, нанотехнологии являются обычными технологиями, и их развитие не нуждается в каком-либо специализированном регулировании. Уже существует достаточный инструментарий этической экспертизы в сфере прикладной этики, который, например, применяется в медицине, и нет необходимости разрабатывать какие-либо особые методы этической экспертизы специально предназначенные для нанотехнологий. Альтернативный подход исходит из того, что нанотехнологии - революционные технологии и это означает, что существующие этические стандарты исследовательской этики недостаточны для регулирования применения нанотехнологий в биомедицине. Следовательно, необходимо разрабатывать новые этические методы в рамках специальной дисциплины - наноэтики, которые позволят адекватно проводить этическую экспертизу всех видов исследований с использованием нанотехнологий.

Социально-эпистемологическая рецепция биотехнологий находит свое отражение в исследованиях науки и технологий (science and technology studies - STS). STS занимаются анализом системных оснований, на которых 
держатся социальные конвенции, определяющие взаимоотношение технологий и общества. Особенно важно то, что в STS признается роль общества и культуры в определении траекторий развития технологий, реализуется идея очищения дискурсов «природы» и дискурсов «культуры» как равноправных акторов, формирующих технологическое пространство. Такие факторы, как ожидание и технологическая мнимость, все чаще выступают в качестве реального вектора, определяющего развитие биотехнологий.

Л. Виннер различает три эпохальных типа взаимоотношений технологий и человека (Winner, 2005), в ходе которых человек технологизирует самого себя: технологии как инструмент и человек как изготовитель инструментов (homo faber), технологии как расширение естественных возможностей человека (зрение, слух и т. п.), технонаука, основанная на идее социально ориентированного развития и конструирования знания.

Все чаще идеи улучшения человека рассматриваются как экспериментальный метод определения биотехнологических рисков. Формально впервые слово «трансгуманизм» использовал биолог Дж. Хаксли для описания будущего человека в одноименной статье (Huxley, 1957). Однако и раньше, в начале XX в., высказывалась идея преобразования человека. Оптимизм в отношении новых сверхвозможностей, не просто изменяющих способности людей, но и освобождающих человека от перспективы недолгой жизни, надежда на преодоление естественных ограничений и болезней, которые мы получаем в силу своей природы, и переход к более высокому качеству жизни, - все это перспективы науки, поддерживаемые трансгуманистами.

В определении биотехнологических рисков большое значение имеют национальные школы социогуманитарной рецепции развития науки. Идея гуманитарной экспертизы как метода анализа научных проектов сформировалась в работах И. Т. Фролова, Б. Г. Юдина, П. Д. Тищенко и других авторов и является реакцией на разработки методов гуманитарных технологий в отечественной философской мысли (Г. П. Щедровицкий) и становление гуманитарного содержания биомедицины в СССР (в работах И. Т. Фролова) (Белкина, Корсаков, 2009).

Социальный и гуманитарный пласты анализа Б. Г. Юдин различает следующим образом: «Прежде всего следует уточнить наше понимание терминов “социальные” и “гуманитарные” применительно к технологиям. Различие между ними довольно простое - там, где речь идет о технологических воздействиях на индивида (или на индивидов), имеет смысл говорить о гуманитарных технологиях (ГТ); там же, где речь идет о воздействиях на социальные общности любого масштаба, имеет смысл говорить о социальных 
технологиях» (Юдин, 2014: 169). Это различие важно для применения гуманитарной экспертизы к биотехнологиям методологически, для разведения индивидуалистского и социального трендов в развитии биотехнологий.

Гуманитарная экспертиза обязана принимать во внимание технологии, которые ориентированы на изменение мнения и даже на манипулирование мнением. Учитывая значение потребителя в контуре технонауки, гуманитарные технологии, основанные на идее проектного мышления и разработке норм в отрыве от истинности, являются серьезным вызовом для гуманитарной экспертизы (там же).

Развитие биотехнологий происходит в сложной социогуманитарной среде, насыщенной концепциями. Общая гетерогенная картина этой среды, с одной стороны, формируется из дискретных исследовательских и экспертных методологий, а с другой стороны, она интегрирована единой проблемой областью: концептуализацией и исследованием рисков, связанных с биотехнологиями. Хотя эти риски могут иметь разные онтологические предпосылки (в зависимости от теоретической концепции, из которой они возникают), они почти всегда становятся частью комплексного соотнесения онтологий рисков и конкретных практик.

\section{ПРОБЛЕМА КОМПЛЕКСНОСТИ}

Каждая из упомянутых методологий предлагает свою онтологию рисков и объясняет их возникновение. Выявление комплексности при реализации технонаучных проектов, которые были исследованы с точки зрения онтологий рисков, - один из наиболее заметных результатов взаимодействия социогуманитарных технологий и науки. В период становления генетики Э. Липман определила ключевые точки рисков генетики: при определении здоровья и болезни генетика становится доминантным дискурсом в профессиональном сообществе и в массовом сознании; генетические дискурсы основываются на редукционизме и детерминизме, и в них утверждается, что гены отвечают за здоровье; общество стратифицируется согласно приоритетам генетики, в обществе формируются иерархии на основании генетической информации; генетизация оказывает влияние на здравоохранение, подчеркивая биологические предпосылки и принижая социальные факторы, ведущие к болезни; повышение качества здоровья в будущем связано с генетическими исследованиями; на генетиков возлагается задача идентификации и классификации проблем, ассоциируемых со здоровьем (Weiner et al., 2017).

Генетические дискурсы стали доминировать (частично) только в лабораториях; прямой детерминизм и редукционизм вытеснены комплексностью; 
общество не стратифицировалось в соответствии с генетическими представлениями; генетические знания оказывают лишь частичное воздействие на предикции общих заболеваний; генетики обладают ограниченными возможностями для пересмотра проблем здоровья. Несмотря на деонтологизацию большинства тезисов Э. Липман о генетизации общества генетические идеи остаются значимым социальным ожиданием как в науке, так и в массмедиа (ibid).

Комплексность - основной результат развития генетики за последние 20 лет, и она проявилась в дублировании генетического и клинического дискурсов и в усложнении практик лечения и диагностики заболеваний. Между тем общество сохранило запрос на генетику как универсальную методологию лечения любых болезней. Гибридная форма технонауки и социогуманитарного анализа рисков сформировала целую парадигму попыток использовать генетику в качестве фактора медицинского понимания болезни.

\section{ЗАКЛЮЧЕНИЕ}

Определение рисков в современной науке уже сложно считать объективистским процессом нахождения наиболее оптимального решения на основе формального, детерминированного философской методологией языка. Социогуманитарные дискурсы риска, безусловно, обогащают науку не только концепциями, но и ракурсом исследования проблемы, но сами они оказываются частью значительного, более сложного процесса гибридизации технологий и социума. Смешивание социального ожидания и биотехнологий, сложности, возникающие при этом, вовсе не заставляют общество и паблики отказываться от, казалось бы, слишком абстрактных и редукционистских моделей описания человека и вместе с тем устанавливают конкуренцию между экспертным сообществом и пабликами. Эпистемологический сдвиг как методология формирования технологической утопии становится матрицей матриц социогуманитарных методологий в оценке риска. Реальность при этом не только не расставляет все точки над $i$, но и не снимает проблему установления жестких границ для развития биотехнологий.

\section{СПИСОК ЛИТЕРАТУРЫ}

Белкина, Г. Л., Корсаков, С. Н. (2009) И. Т. Фролов и становление отечественной биоэтики // Биоэтика и гуманитарная экспертиза. Вып. 2. М. : ИФ PAH. 230 c. C. $18-54$.

Попова, О. В. (2017) Конструирование «человека-как-испытуемого» // Биоэтика. №. 2 (20). С. 17-21. 
Тищенко, П. Д. (1992) Феномен биоэтики // Вопросы философии. № 3. C. 104-113.

Юдин, Б. Г. (2014) От гуманитарного знания к гуманитарным технологиям // Гуманитарные ориентиры научного познания / отв. ред. П. Д. Тищенко. М. : Навигатор. 352 с. С. 159-173.

Grunwald, A. (2005) Nanotechnology - A new field of ethical inquiry? // Science and Engineering Ethics. Vol. 11. No. 2. P. 187-201. DOI: 10.1007/s11948-005-0041-0

Huxley, J. (1957) Transhumanism // Huxley J. New bottles for new wine : essays. L. : Chatto \& Windus. 318 p. P. 13-17.

Jonsen, A. R. (2004) The history of bioethics as a discipline // Handbook of bioethics: Taking stock of the field from a philosophical perspective / ed. by G. Khushf. Dordrecht ; Boston : Kluwer Academic Publishers. vi, 568 p. P. 31-51.

Rommetveit, K., Wynne, B. (2017) Technoscience, imagined publics and public imaginations // Public Understanding of Science. Vol. 26. No. 2. P. 133-147. DOI: $10.1177 / 0963662516663057$

Weiner, K. et al. (2017) Have we seen the geneticisation of society? Expectations and evidence / K. Weiner, P. Martin, M. Richards, R. Tutton // Sociology of Health \& Illness. Vol. 39. No. 7. P. 989-1004. DOI: 10.1111/1467-9566.12551

Winner, L. (2005) Resistance is futile: The posthuman condition and its advocates // Is human nature obsolete? Genetics, bioengineering, and the future of the human condition / ed. by H. W. Baillie, T. K. Casey. Cambridge, MA : MIT Press. x, 422 p. P. 385-411.

Yudin, B. G. (2010) Research on humans at the Khabarovsk War Crimes Trial: A historical and ethical examination // Japan's wartime medical atrocities: Comparative inquiries in science, history, and ethics / ed. by Jing-Bao Nie, Nanyan Guo, M. Selden, A. Kleinman. L. ; N. Y. : Routledge. xviii, 249 p. P. 59-78.

Дата поступления: 26.08.2018 2.

Белялетдинов Роман Рифатович — младший научный сотрудник сектора гуманитарных экспертиз и биоэтики Института философии Российской академии наук. Адрес: 109240, Россия, г. Москва, ул. Гончарная, д. 12, стр. 1. Тел.: +7 (495) 697-90-67. Эл. адрес: roman_rb@iph.ras.ru

Belyaletdinov Roman Rifatovich, Junior Research Fellow, Department of Humanitarian Expertise and Bioethics, Institute of Philosophy, Russian Academy of Sciences. Postal address: Bldg. 1, 12, Goncharnaya St., 109240 Moscow, Russian Federation. Tel.: +7 (495) 697-90-67. E-mail: roman_rb@iph.ras.ru 
ORCID: 0000-0003-1420-0022

Researcher ID: $\underline{\text { U-9178-2018 }}$

Для цитирования:

Белялетдинов Р. Р. Онтологии биотехнологических рисков: социогуманитарные методологии и технонаука [Электронный ресурс] // Горизонты гуманитарного знания. 2018. № 5. С. 29-38. URL: http://journals.mosgu.ru/ggz/ article/view/855 (дата обращения: дд.мм.гггг). DOI: 10.17805/ggz.2018.5.3 